\title{
Competência leitora de alunos do ensino fundamental em textos da literatura infanto-juvenil
}

\section{Manuella Soares ${ }^{1}$ \\ Maria do Socorro Paz e Albuquerque ${ }^{2}$}

Resumo: Este trabalho objetiva apresentar os resultados obtidos na realização do projeto de pesquisa: Competência leitora de alunos do ensino fundamental em textos da literatura infantojuvenil ${ }^{3}$ - PIBIC, 20102011, que buscou responder a questão: que competência leitora alunos do $9^{\circ}$ ano do $\mathrm{EF}$ dominam após intervenção sistemática de práticas de leitura com textos da literatura infanto-juvenil? Fundamentamo-nos nas seguintes perspectivas teóricas: sociointeracionista de leitura em Kato (1998); Kleiman (1989, 1992), Solé (1998), nos PCN de língua Portuguesa (1998), e orientações sobre o ensino da literatura em Zilberman (1983) e no conceito de competência de Perrenoud (2002). Em relação à metodologia, optamos por seguir as orientações da pesquisa-ação, (THIOLLENT, 2005; FRANCO, 2005) uma vez que foram professores de uma escola pública de Campina Grande - PB que solicitaram a nossa intervenção conjunta para encontrarmos a solução para o problema do desestímulo e das dificuldades de leitura apresentadas pelos alunos do $9^{\circ}$ ano da referida escola. Para isto, foi feito um diagnóstico inicial, com base nos descritores da Prova Brasil; em seguida, realizou-se uma intervenção didático-pedagógica, que trabalhou mais especificamente as competências não adquiridas, tendo como base a leitura de textos da literatura infanto-juvenil, especificamente do gênero crônica. Por último, aplicou-se um pós-teste, também com base nos mesmos descritores para identificar e descrever as competências em leitura adquiridas pelos alunos. Após a intervenção didática e análise do pré-teste e do pós-teste, pudemos observar os efeitos dessa intervenção na formação do leitor competente.

Palavras-chave: Competência leitora. Didatização. Formação de leitor.

Abstract: This study aims to answer the question: what competence reader students in 9th grade after intervention of the EF dominate systematic practices of reading texts with children's literature? To do this, fundamentals in the following theoretical perspectives: sociointeracionista reading in NCP and Portuguese speaking guidance on the teaching of literature and the concept of competence Perrenoud (2002). Regarding methodology, we chose to follow the guidelines of action research, since they were teachers at a public school in Campina Grande - PB requested that our joint intervention to find a solution to the problem of discouragement and reading difficulties presented by students in the 9th year of that school. For this, he was made an initial diagnosis based on descriptors of Proof Brazil, then there was a didactic-pedagogic intervention that worked competences not acquired, based on the reading of texts of children's literature, specifically chronic gender. Finally, we applied a post-test, also based on the same descriptors to identify and describe the skills acquired by students in reading. After the intervention, and didactic analysis of the pre-test and post-test, we observed the effects of this intervention in the formation of the competent reader.

Keywords: Competence reader. Didactization. Formation reader.

\section{Introdução}

\footnotetext{
1 Aluna do curso de Letras, Unidade Acadêmica de Letras, UFCG, Campina Grande, PB, E-mail: manuellaufcg@hotmail.com.

${ }^{2}$ Professora. Doutora, Unidade Acadêmica de Letras, UFCG, Campina Grande, PB, E-mail: ms_paz@ig.com.br.

${ }^{3}$ Esse projeto obteve a $1^{\text {a }}$ colocação na Grande Área de Ciências Humanas, Sociais e Linguística na premiação do VIII Congresso de Iniciação Científica da UFCG, realizado no período de 25-27 de outubro de 2011, em Campina Grande-PB.
} 
Viver em uma sociedade letrada, em que a leitura e a escrita constituem práticas sociais que permeiam as relações entre os sujeitos e, destes com o mundo, faz com que haja a necessidade de a escola formar leitores competentes. Voltada para esta questão, a educação deve estar pautada na formação de cidadãos críticos e capazes de interpretar e escrever textos dos mais variados gêneros.

Convictos dessa responsabilidade, propomo-nos a investigar as dificuldades de leitura apresentadas por alunos do $9^{\circ}$ ano da Escola Estadual Prof. Hortênsio de Souza Ribeiro (PREMEN), de Campina Grande, apontadas pelos professores dessa instituição, manifestado por um pedido de auxílio para o trabalho com o texto literário, uma vez que esse se caracteriza pela possibilidade de atribuição de diferentes sentidos, causado pela subjetividade que o constitui. Segundo os professores, essa seria uma das principais causas do desestímulo, por parte dos alunos, para a leitura, considerando-a de difícil compreensão.

Assim, neste trabalho, objetivamos mostrar os resultados do projeto Competência leitora de alunos do Ensino Fundamental em textos da literatura infantojuvenil, relacionados às competências leitoras demonstradas pelos alunos envolvidos na pesquisa, na primeira fase - pré-teste -, assim como comparar esses resultados com os dos pós-testes, após a intervenção didático-pedagógica, voltada, sobretudo, para o desenvolvimento das competências não demonstradas pelos alunos. Também discutiremos os efeitos da intervenção didática para a formação do leitor competente, tendo em vista a participação destes na Prova Brasil e no PISA, em 2011.

\section{Fundamentação teórica}

\subsection{Estudos sobre leitura}

As pesquisas em educação e linguagem, nesses últimos cinqüenta anos, muito têm avançado no sentido de compreendermos a complexidade que envolve a leitura e o como fazer para formar leitores. Há um consenso quanto a Ler - não é apenas decodificar- e implica, principalmente em saber usar a tecnologia da leitura e da escrita para atender às necessidades sociais do leitor, enquanto sujeito inserido num contexto (perspectiva do letramento) e saber interpretar o mundo, relacionando o sentido a aspectos sociais, históricos e ideológicos, dando conta das relações que se estabelecem entre os gêneros textuais, nas esferas sociais, considerando a enunciação com suas imbricações histórica e ideológica (visão sócio- 
histórica), e as formações discursivas relacionando discursos a outros discursos através de textos (Análise do discurso).

O MEC tem tomado algumas providências em torno da questão da ineficácia das orientações teórico-metodológicas utilizadas na escola para a formação do leitor e uma de suas medidas para as políticas educacionais é aplicar exames que visam diagnosticar a capacidade de leitura de alunos do EF e do Ensino Médio para verificar a construção de uma das competências centrais do letramento: a leitora.

Para avaliar a competência leitora dos alunos temos dois órgãos - no ensino básico o SAEB (Sistema de Avaliação da Educação Básica) e a Prova Brasil e, no médio, o ENEM (Exame Nacional do Ensino Médio), ambos governamentais. A Prova Brasil visa avaliar o desempenho em língua portuguesa e matemática de estudantes do $5^{\circ}$ ao $9^{\circ}$ anos de escolas públicas. Com os resultados do exame, é possível fazer um diagnóstico da situação nacional e regional da educação no país. Os dados são utilizados para calcular o Índice de Desenvolvimento da Educação Básica (Ideb) e melhorar a qualidade do ensino básico, uma das metas do Plano de Desenvolvimento da Educação (PDE).

Embora seja o diagnóstico necessário para a identificação dos problemas, as soluções não chegam de imediato apenas por que foram localizados. E como a competência leitora continua sendo uma das grandes metas do ensino, os PCN-LP não poderiam deixar de enfatizar e apontar caminhos para que o professor conduza seu aluno à conquista dessa habilidade. Dentre os modelos interacionistas de leitura, o que fundamenta os PCN-LP é desenvolvido aqui no Brasil por Kato (1987, 1998); Kleiman (1989, 1992) - autora citada na referência bibliográfica dos PCN-LP - dentre outros. Esse modelo interacionista inclui fatores sociais no processo de compreensão ao enfocar as intenções de significação do autor para o texto em que a compreensão se processa à distância entre leitor e autor via texto (KLEIMAN, 1989, p. 65).

No conceito de leitura dos PCN-LP, há a referência à abordagem cognitivista - no que concerne às estratégias de leitura que o leitor utiliza no processo da compreensão - conforme constatamos nessa citação: "qualquer leitor experiente constatará que a leitura fluente envolve uma série de outras estratégias como seleção, antecipação, inferência e verificação, sem as quais não é possível rapidez e proficiência. (PCN-LP, 1997b, p. 53).

Também apontadas por Isabel Solé (1998, p.73), as estratégias de leitura "devem permitir que o aluno planeje sua tarefa geral de leitura e sua própria localização - motivação, 
disponibilidade" que lhe permitirá a comprovação, a revisão, o controle do que lê e a tomada de decisões adequada em função dos objetivos da leitura. Esta autora define estratégia de leitura como sendo o emprego de esquemas ou procedimentos, por um leitor, para obter, avaliar e servir-se de uma informação presente no texto. Essas estratégias devem esclarecer o leitor sobre os objetivos da leitura, o que fazer e o que saber conforme as orientações dadas para a compreensão.

Outra concepção sobre leitura e formação do leitor, de caráter predominantemente social dos PCN-LP é a do Letramento. Nesses parâmetros, Letramento "é entendido como produto da participação em práticas sociais que usam a escrita como sistema simbólico e tecnologia (...).” (PCN-LP, 1997b, p. 23). A partir dessa perspectiva, os PCN-LP mostram que uma das funções sociais da escola é a formação de cidadãos críticos e atuantes que sabem se utilizar das práticas sociais da leitura e da escrita. Dessa forma, o sujeito deve atuar e ter acesso à linguagem do poder para nela interferir, utilizando-a em seu benefício. (SOARES, 1986).

Nessa perspectiva, o ensino/aprendizagem da leitura objetiva formar um leitor que tenha participação social, isto é, que seja capaz de interpretar e produzir textos que atendam às suas necessidades sociais, exercendo a sua cidadania. Para os PCN-LP, leitor competente é aquele que entende o que lê, não apenas decodifica, lê o que está implícito, sabe que o texto estabelece relações intertextuais e pode ter vários sentidos.

\subsection{Os PCN-LP e o texto literário}

Os PCN-LP afirmam que tendo em vista que o texto literário destaca-se pela ficcionalidade, o tratamento dado a esses textos não deve limitar-se à leitura esporádica de textos de determinado estilo, mas deve passar desta a uma prática de leitura por parte dos alunos que envolva a relação entre textos diferentes, a relação entre literatura como meio de estudo da cultura e do social. (PCN-LP, 1998, p. 26-27). Além disso, a linguagem peculiar do texto literário (mais especificamente, do texto poético) permite uma abordagem que envolva a construção de sentidos específicos dentro do texto (através da linguagem metafórica), o que não ocorre em outros gêneros.

O contato proporcionado pelo professor com o texto literário deve ter como ponto de partida as obras apreciadas pelo aluno, e deve ser acompanhado do incentivo à leitura extraclasse também de obras de interesse do mesmo. O estímulo a essa prática constante da leitura 
será resultado das leituras feitas em sala de aula, que levarão o aluno a abordar o texto literário de forma abrangente e reflexiva, relacionando informações a situações de seu mundo, a outros textos, a conhecimentos históricos e culturais. Podemos constatar essa abordagem nas palavras de Zilberman, ao afirmar que a literatura

\begin{abstract}
“(...) sintetiza, por meio de recursos da ficção uma realidade, que tem amplos pontos de contato com o que o leitor vive cotidianamente. Assim, por mais exacerbada que seja a fantasia do escritor ou mais distanciadas e diferentes as circunstâncias de espaço e tempo dentro das quais uma obra foi concebida, o sintoma de sua sobrevivência é o fato de que ela continua a se comunicar com seu destinatário atual, porque ainda fala de seu mundo, com suas dificuldades e soluções, ajudando-o, pois, a conhecê-lo melhor" (ZILBERMAN, 1983, p. 22).
\end{abstract}

Além dessa perspectiva pedagógica, em sala de aula, sabemos que o incentivo à leitura depende também do fato de o professor ser um leitor que aprecia o texto literário.

\title{
2.3. Conceito de competências e habilidades em leitura segundo o SAEB
}

A elaboração dos itens/questões do SAEB e da Prova Brasil tem como base uma associação entre os conteúdos da aprendizagem e as competências utilizadas no processo de construção do conhecimento. No documento SAEB 2011: Novas Perspectivas (2002), competência é definida, na perspectiva de Perrenoud (2002), como sendo a "capacidade de agir eficazmente em um determinado tipo de situação, apoiando-se em conhecimentos, mas em se limitar a eles". Para enfrentar uma situação, geralmente, colocam-se em ação vários recursos cognitivos do sujeito. Para Perrenoud, "quase toda ação mobiliza alguns conhecimentos, algumas vezes elementares e esparsos, outras vezes complexos e organizados em rede".

Quanto ao conceito de Habilidades, também em Perrenoud (2002), nesse mesmo documento, refere-se, especificamente, ao plano objetivo e prático do saber fazer que decorre, diretamente, das competências já adquiridas que se transformam em habilidades. Assim, a competência leitora implica na aquisição/domínio de estratégias de leitura, que dão ao leitor habilidades para ler e interpretar textos de gêneros diversos, incluindo os literários, em situações diferentes e atendendo às suas necessidades.

A Matriz de Referência de Língua Portuguesa que fundamenta a elaboração da Prova Brasil e do SAEB apresenta a relação entre os temas, os descritores e as habilidades 
estabelecidas para a avaliação dos alunos da $3^{\text {a }}$ série do Ensino Médio (EM). O descritor é uma associação entre conteúdos curriculares e operações mentais desenvolvidas pelo aluno, que traduzem certas competências e habilidades de leitura. Os descritores indicam habilidades gerais que se esperam dos alunos e constituem a referência para seleção dos itens que devem compor uma prova de avaliação.

\subsection{Estudos sobre Didatização}

Albuquerque (2007) analisando a didatização do conceito de leitor competente dos PCN-LP, na formação de formadores do Programa Parâmetros em Ação, verificou que o saber teórico sobre leitura presente nesses documentos se apresentava "diferente" nas etapas de formação dos formadores como também pelos professores alfabetizadores em sala de aula. Essa diferença não é considerada problemática uma vez que ela caracteriza o processo natural da didatização - as mudanças que ocorrem com o saber científico ou teórico ao ser ensinado em sala de aula. Por saber científico entenda-se o saber produzido nas academias, instituições de produção científica e que é apresentado à comunidade científica através de artigos, teses, livros especializados e relatórios. Daí a necessidade de adequá-la à linguagem escolar, fazendo "pontes" entre o saber científico e o saber a ser ensinado na escola. O professor necessita passar por essa reflexão e agir de forma teórico-metodológica que propicie a aquisição das competências leitoras dos alunos sem que para isso negligencie no seu agir pedagógico sobestimando a capacidade de aprendizagem desses alunos.

\section{Metodologia}

\subsection{Contextualização da pesquisa e de sua ação teórico-metodológica}

A caracterização teórico-metodológica do projeto Competência leitora de alunos do Ensino Fundamental em textos da literatura infantojuvenil compreende a pesquisa-ação colaborativa que, segundo Franco (2005, p.485), consiste em um trabalho de cooperação entre pesquisador e o grupo ao qual se destina a pesquisa. Esta está relacionada à atitude do grupo que necessita de auxílio, devendo partir dele o interesse pela busca de resolução de problemas e transformações. Por isso, a pesquisa-ação também está fundamentada na observação da prática educativa, ganhando um caráter de 
"pesquisa eminentemente pedagógica, dentro da perspectiva de ser o exercício pedagógico, configurado como uma ação que cientifica a prática educativa, a partir de princípios éticos que visualizam a contínua formação e emancipação de todos os sujeitos da prática" (FRANCO, 2005, p. 483)

A nossa proposta de pesquisa surgiu a partir do pedido de ajuda por parte da equipe de professores da Escola Estadual Dr. Hortênsio de Souza Ribeiro (PREMEN), da cidade de Campina Grande - PB, acerca da dificuldade de suscitar nos alunos o interesse pela leitura de textos da literatura infanto-juvenil, os quais demonstravam desestímulo em relação ao ato de ler.

Após a aplicação do pré-teste, que compreendia 12 questões retiradas da Prova Brasil 2009 e identificação dos descritores que representaram dificuldades para os alunos, iniciamos a intervenção didático-pedagógica com a correção das mesmas. Em seguida, a didatização do gênero crônica, por considerarmos sua linguagem acessível à faixa etária dos alunos, além de propiciar o trabalho com as possibilidades de vários sentidos que o texto literário permite. Essa etapa consistiu no trabalho com as dificuldades apresentadas no pré-teste, visando garantir aos alunos a aquisição de competências que não foram demonstradas. Concluída a intervenção, aplicamos um pós-teste para verificarmos se as competências não adquiridas teriam sido desenvolvidas após o trabalho minucioso e específico, voltado exclusivamente para as necessidades desses alunos. A intervenção foi realizada em três turmas do $9^{\circ}$ ano do E. F., que constava de duas aulas semanais em cada turma, durante o período de três meses.

As crônicas escolhidas foram Atitude suspeita, Palavreado e Defenestração, de autoria de Luís Fernando Veríssimo, retiradas, a primeira do Livro Didático (LD) adotado pela escola e as outras do livro desse autor "Crônicas para se ler na escola" (2008). Para a intervenção, elaboramos uma sequência didática para a leitura e interpretação do gênero crônica apoiadas em procedimentos e estratégias de leitura, Kleiman (1992); leitura colaborativa, PCN-LP. Em seguida a caracterização e compreensão do gênero, oportunizamos a produção de atividades escritas sobre as crônicas, segundo as perspectivas sociointeracionistas de leitura. Como não é objetivo deste artigo, não será possível apresentar as atividades realizadas.

\section{Resultados e discussão}

Analisaremos, nesta seção, os resultados do pré-teste e do pós-teste com base no percentual de acertos e teceremos alguns comentários acerca dos resultados obtidos em cada 
um dos descritores. Para isso, apresentaremos um quadro comparativo entre os resultados de ambos.

\subsection{Análise do Pré-teste}

\begin{tabular}{|c|c|c|c|}
\hline DESCRITOR & COMPETÊNCIA & ACERTOS & ERROS \\
\hline D3 & Inferir o sentido de uma palavra ou expressão & $32,3 \%$ & $67,7 \%$ \\
\hline D4 & Inferir uma informação implícita em um texto & $51,1 \%$ & $48,2 \%$ \\
\hline D6 & Identificar o tema de um texto & $73,3 \%$ & $26,7 \%$ \\
\hline D7 & Identificar a tese de um texto & $70,0 \%$ & $30,0 \%$ \\
\hline D8 & $\begin{array}{l}\text { Estabelecer relações entre a tese e os } \\
\text { argumentos oferecidos para sustentá-la }\end{array}$ & $70,0 \%$ & $30,0 \%$ \\
\hline D10 & $\begin{array}{c}\text { Identificar o conflito gerador do enredo e os } \\
\text { elementos que constituem a narrativa }\end{array}$ & $34,4 \%$ & $65,6 \%$ \\
\hline D11 & $\begin{array}{l}\text { Estabelecer relação entre causa/consequência } \\
\text { entre partes e elementos do texto }\end{array}$ & $16,6 \%$ & $83,4 \%$ \\
\hline D14 & $\begin{array}{l}\text { Distinguir um fato da opinião } \\
\text { relativa a esse fato }\end{array}$ & $74,4 \%$ & $25,6 \%$ \\
\hline D16 & $\begin{array}{c}\text { Identificar efeitos de ironia ou } \\
\text { humor em textos variados }\end{array}$ & $35,5 \%$ & $64,5 \%$ \\
\hline D17 & $\begin{array}{l}\text { Identificar o sentido decorrente do uso } \\
\text { da pontuação e de outras notações }\end{array}$ & $14,4 \%$ & $85,6 \%$ \\
\hline D18 & $\begin{array}{c}\text { Reconhecer o efeito de sentido decorrente da } \\
\text { escolha de uma determinada palavra ou expressão }\end{array}$ & $26,6 \%$ & $73,4 \%$ \\
\hline D19 & $\begin{array}{c}\text { Reconhecer o efeito de sentido decorrente da } \\
\text { exploração de recursos ortográficos e/ou } \\
\text { morfossintáticos }\end{array}$ & $38,8 \%$ & $61,2 \%$ \\
\hline
\end{tabular}

Quadro 1: Resultado obtido na etapa de pré-teste

Diante dos resultados apresentados no pré-teste realizado com alunos do $9^{\circ}$ ano da $\mathrm{E}$. E. E. F. M. Prof. Hortênsio de Souza, tendo como base os descritores da Prova Brasil 2009, podemos afirmar que eles:

- demonstraram bons resultados nos seguintes descritores: D4 - Inferir uma informação implícita em um texto (51, 1\%); D6 - Identificar o tema de um texto (73, 3\%); D14 - Distinguir um fato da opinião relativa a esse fato (74, 4\%); D7 - Identificar a tese de um texto (70,0\%); e D8 - Estabelecer relação entre a tese e os argumentos oferecidos para sustentá-la $(70,0 \%)$; 
- não apresentaram dificuldades em inferir uma informação implícita no texto $O$ império da vaidade, de Paulo Moreira Leite (D4), quando lhes foi pedido para marcar a opção que correspondia à intenção do autor ao pretender influenciar os leitores a terem uma visão crítica diante do incentivo do consumo pela mídia. Com isso, os alunos demonstraram entender a questão ao identificar a informação que estava "escondida" no texto, obtendo o resultado de $51,1 \%$;

- conseguiram identificar o tema do texto A paranóia do corpo, de Letícia de Castro (D6). Quando impelidos a apontar a ideia central do texto, souberam responder de maneira satisfatória e identificar o que o mesmo trazia como foco, apresentando 73,3\% de acertos.

- souberam ainda identificar a tese (D7), presente no artigo O ouro da biotecnologia, de Daniel Piza, apresentando o bom resultado - 70, 0\%. Isso mostra que o que era defendido pelo autor foi compreendido pelos alunos.

Unido a esse resultado, também demonstraram facilidade para estabelecer relações entre a tese apontada e o argumento oferecido para sustentá-la (D8) por Marta Suplicy em seu texto $O$ namoro na adolescência - 70,0\%. Nessa questão, se pedia que os leitores identificassem o argumento que defendia a ideia apresentada pela autora.

Dentre os bons índices de acertos, está a resposta ao descritor 14 - distinguir um fato da opinião relativa a esse fato - ao identificar o fato relatado no texto No mundo dos sinais, retirado do Jornal do Telecurso da TV Cultura, diferenciando-o da opinião de seu autor (D14). A questão trazia em suas alternativas trechos do próprio texto em análise e pedia que os alunos apontassem qual deles expunha a opinião do autor; tal distinção foi compreendida por quase todos os alunos: $74,4 \%$.

Analisando as respostas de resultados insatisfatórios no pré-teste, observamos que os alunos envolvidos demonstraram dificuldades em várias tarefas requeridas por alguns descritores. A questão que representa o menor resultado dentre todos os outros $-14,4 \%$ - foi a de identificar o sentido decorrente do uso da pontuação e de outras notações (D17). Mais especificamente, era pedido aos alunos que identificassem na charge Romeu e Dalila, de Angeli o sentido do uso do ponto de exclamação no terceiro quadrinho, que correspondia a “desinteresse" no contexto da tirinha. Porém, muitos dos alunos - 85,6\% - responderam que o sentido dessa pontuação correspondia à "surpresa", o que nos faz inferir que eles não atentaram para o contexto situacional do uso da exclamação, mas apenas para a concepção gramatical comumente dada ao seu uso, com a função de surpresa e emoção. 
Um outro dado que comprova resultados não satisfatórios se relaciona à dificuldade no estabelecimento da relação causa/consequência entre partes e elementos de texto (D11). A partir da leitura do texto-base $O$ homem que entrou pelo cano, de Ignácio de Loyola Brandão, se pedia a identificação da causa de uma determinada ação no texto, a qual obteve $83,4 \%$ de erros, indicando que a grande parte dos alunos não soube entender a organização textual, embora sendo este um texto narrativo em que os elementos se relacionam de maneira que um torna-se resultado do outro.

Quanto ao descritor 18, o qual exige o reconhecimento do efeito de sentido decorrente da escolha de uma determinada palavra ou expressão, presente na questão 12 na qual se pedia que o leitor identificasse o sentido da palavra "Cavalheiro" no texto "Chatear" $e$ "encher", de Paulo Mendes Campos os alunos apresentam dificuldades. No contexto apresentado, a palavra emitia um efeito de sentido de "impaciência" da personagem, e não de gentileza sentido denotativo da palavra em análise - apontado por 73,4\% dos alunos. Mais uma vez, comprovamos que eles não analisaram o contexto no qual a expressão se apresentava e as possibilidades de efeitos de sentido que o texto literário permite, no caso, a crônica.

Unido a esse descritor está o descritor 3, a partir do qual espera-se que seja inferido o sentido de uma palavra ou expressão de um texto. Com base no texto $O$ pavão, de Rubem Braga, era exigido o sentido da expressão "atingir o máximo de matizes", o que levou a maioria dos alunos - 67, 7\% - a fazerem a associação da mesma com a alternativa que trazia uma informação que denotava quantificação, relacionando-a ao termo "máximo" da expressão destacada do texto. Podemos inferir, dessa forma, que os alunos não conseguiram compreender o sentido da expressão no contexto e sim estabelecer relações apenas entre palavras que traziam valores semânticos parecidos.

Em relação à identificação de efeitos de ironia ou humor em textos variados (D16), grande parte dos alunos - 64, 5\% - não soube identificar, na tirinha $O$ pato no formigueiro, de Ciça, o humor da personagem - uma formiga - com o verbo "pechinchar". Podemos inferir que, pelo fato de o primeiro quadrinho ter trazido os dígrafos " $\mathrm{x}$ " $\mathrm{e}$ "ch" por extenso e em negrito, causou certa confusão no momento de perceber o que tornava toda a tirinha engraçada.

Resultado semelhante a esse descritor é o do descritor 19, que demanda o reconhecimento do efeito de sentido decorrente da exploração de recursos ortográficos e/ou morfossintáticos. A questão produzida com base nesse descritor pedia que, a partir do texto $A$ 
chuva, de Arnaldo Antunes, fosse identificada a função do uso do recurso da repetição do termo "a chuva" no início de todas as frases que o compunham, tendo como resposta a sugestão da intensidade e da continuidade da chuva. A maioria dos alunos - 61, 2\% - alegou ser o texto enfadonho e que certo cansaço é gerado pela repetição de uma única expressão, não percebendo o efeito de sentido conotativo desse uso.

Finalizando o grupo dos resultados não satisfatórios, está a questão 10, fundamentada no descritor 10, que aborda a identificação do conflito gerador do enredo e os elementos que constroem a narrativa. Essa questão do pré-teste exigia que, após a leitura da fábula Urubus $e$ sabiás, de Rubem Alves, os alunos identificassem, naquele contexto específico, o fato que gerou o conflito, tendo como resposta "o desejo dos urubus de aprender a cantar". O baixo resultado - 34,4\% - pode ter sido causado pelo não conhecimento por parte dos alunos de conceitos relacionados ao conflito gerador da narrativa, o que nos faz inferir que tal fato é decorrente do estudo superficial que o Livro Didático faz acerca dos elementos da narrativa no Ensino Fundamental, ampliando-o somente no Ensino Médio.

\subsection{Análise do Pós-teste}

A aplicação do pós-teste foi realizada com 32 alunos, sendo que apenas 22 desses fizeram o pré-teste, constituindo o corpus de nossa análise final, em que procederemos à comparação entre os resultados das duas etapas. Deter-nos-emos à análise do pós-teste com a pretensão de verificar se as dificuldades dos alunos em relação a alguns descritores no préteste foram superadas, e se as competências mensuradas por cada um deles foram adquiridas.

A partir do quadro abaixo, teceremos comentários acerca do pós-teste. 


\begin{tabular}{|c|c|c|c|c|}
\hline DESCRITOR & COMPETÊNCIA & QUESTÃO & ACERTOS & ERROS \\
\hline \multirow[t]{4}{*}{ D6 } & Identificar o tema de um texto & 1 & $45,45 \%$ & $54,55 \%$ \\
\hline & & 5 & $13,63 \%$ & $86,37 \%$ \\
\hline & & 8 & $18,18 \%$ & $81,82 \%$ \\
\hline & & 12 & $59,09 \%$ & $40,91 \%$ \\
\hline \multirow[t]{2}{*}{ D12 } & $\begin{array}{l}\text { Identificar a finalidade de textos de } \\
\text { diferentes gêneros }\end{array}$ & 2 & $9,09 \%$ & $90,91 \%$ \\
\hline & & 11 & $31,81 \%$ & $68,19 \%$ \\
\hline D15 & $\begin{array}{c}\text { Estabelecer relações lógico- } \\
\text { discursivas presentes no texto } \\
\text { marcadas por conjunções, advérbios } \\
\text { etc. }\end{array}$ & 3 & $72,72 \%$ & $27,28 \%$ \\
\hline D17 & $\begin{array}{c}\text { Reconhecer o efeito de sentido } \\
\text { decorrente do uso da pontuação e de } \\
\text { outras notações }\end{array}$ & 4 & $72,72 \%$ & $27,28 \%$ \\
\hline D14 & $\begin{array}{l}\text { Distinguir um fato da opinião relativa } \\
\text { a esse fato }\end{array}$ & 6 & $31,81 \%$ & $68,19 \%$ \\
\hline D4 & $\begin{array}{l}\text { Inferir uma informação implícita em } \\
\text { um texto }\end{array}$ & 7 & $59,09 \%$ & $40,91 \%$ \\
\hline D10 & $\begin{array}{c}\text { Identificar o conflito gerador do } \\
\text { enredo e os elementos que constroem } \\
\text { a narrativa }\end{array}$ & 14 & $86,36 \%$ & $13,64 \%$ \\
\hline D16 & $\begin{array}{l}\text { Identificar efeitos de ironia ou humor } \\
\text { em textos variados }\end{array}$ & 16 & $52,17 \%$ & $47,83 \%$ \\
\hline \multirow[t]{4}{*}{ D3 } & $\begin{array}{l}\text { Inferir o sentido de uma palavra ou } \\
\text { expressão }\end{array}$ & 9 & $45,45 \%$ & $54,55 \%$ \\
\hline & & 10 & $59,09 \%$ & $40,91 \%$ \\
\hline & & 13 & $31,81 \%$ & $68,19 \%$ \\
\hline & & $\begin{array}{c}15 \\
\text { (Anulada) }\end{array}$ & / & I \\
\hline
\end{tabular}

Quadro 2: Resultado obtido na etapa de pós-teste

\subsection{As competências leitoras adquiridas após a intervenção didático-pedagógica}

Após a análise dos resultados do pré-teste e do pós-teste, procederemos a uma análise comparativa entre ambas para verificar os efeitos da intervenção didático-pedagógica na aquisição da competência leitora pelos alunos. Para uma melhor visualização, construímos o seguinte quadro comparativo:

Quadro 3: Comparação entre os resultados obtidos nas etapas de pré-teste e pós-teste

\begin{tabular}{|c|c|c|c|c|}
\hline DESCRITOR & COMPETÊNCIA & $\begin{array}{c}\text { PRÉ- } \\
\text { TESTE }\end{array}$ & $\begin{array}{c}\text { PÓS- } \\
\text { TESTE }\end{array}$ & $\begin{array}{c}\text { RESULTADOS } \\
\text { Aumento ( + ) } \\
\text { Queda ( - ) }\end{array}$ \\
\hline D3 & Inferir o sentido de uma palavra ou & $18,18 \%$ & $45,45 \%$ & + \\
\hline
\end{tabular}




\begin{tabular}{|c|c|c|c|c|}
\hline & expressão & & & \\
\hline D4 & $\begin{array}{l}\text { Inferir uma informação implícita em um } \\
\text { texto }\end{array}$ & $40,9 \%$ & $59,09 \%$ & + \\
\hline D6 & Identificar o tema de um texto & $59,9 \%$ & $34,08 \%$ & - \\
\hline D7 & Identificar a tese de um texto & $68,18 \%$ & I & \\
\hline D8 & $\begin{array}{l}\text { Estabelecer relações entre a tese e os } \\
\text { argumentos oferecidos para sustentá-la }\end{array}$ & $81,81 \%$ & I & I \\
\hline D10 & $\begin{array}{l}\text { Identificar o conflito gerador do enredo e } \\
\text { os elementos que constituem a narrativa }\end{array}$ & $63,63 \%$ & $86,36 \%$ & + \\
\hline D11 & $\begin{array}{c}\text { Estabelecer relação entre } \\
\text { causa/consequência entre partes e } \\
\text { elementos do texto }\end{array}$ & $9,09 \%$ & I & I \\
\hline D14 & $\begin{array}{l}\text { Distinguir um fato da opinião relativa a } \\
\text { esse fato }\end{array}$ & $81,81 \%$ & $31,81 \%$ & - \\
\hline D16 & $\begin{array}{c}\text { Identificar efeitos de ironia ou humor em } \\
\text { textos variados }\end{array}$ & $40,9 \%$ & $52,17 \%$ & + \\
\hline D17 & $\begin{array}{l}\text { Identificar o sentido decorrente do uso da } \\
\text { pontuação e de outras notações }\end{array}$ & $40,54 \%$ & $72,72 \%$ & + \\
\hline D18 & $\begin{array}{l}\text { Reconhecer o efeito de sentido decorrente } \\
\text { da escolha de uma determinada palavra } \\
\text { ou expressão }\end{array}$ & $31,81 \%$ & / & I \\
\hline D19 & $\begin{array}{l}\text { Reconhecer o efeito de sentido decorrente } \\
\text { da exploração de recursos ortográficos } \\
\text { e/ou morfossintáticos }\end{array}$ & $40,9 \%$ & / & I \\
\hline
\end{tabular}

$\mathrm{Na}$ fase de pré-teste, os alunos demonstraram as competências relacionadas aos seguintes descritores: D6 - Identificar o tema de um texto (59, 9\%); D7 - Identificar a tese de um texto $(68,18 \%)$; D8 - Estabelecer relação entre a tese e os argumentos oferecidos para sustentá-la (81, 81\%); D10 - Identificar o conflito gerador do enredo e os elementos que constroem a narrativa $(63,63 \%)$; e D14 - Distinguir um fato da opinião relativa a esse fato $(81,81 \%)$.

Após a aplicação do pós-teste, pudemos analisar os resultados, compará-los com os resultados do pré-teste e verificar se a intervenção didático- pedagógica favoreceu à aquisição das competências não demonstradas pelos alunos na etapa inicial (pré-teste). Vale salientar que os resultados analisados correspondem aos apresentados por 22 alunos que participaram do pré-teste, da intervenção e do pós-teste. No descritor 3, a partir do qual se espera que o leitor seja capaz de inferir o sentido de uma palavra ou expressão, observamos um aumento $(18,18 \% \rightarrow 45,45 \%)$, apesar de não conseguir atingir a meta dos $50 \%$ - o esperado para considerarmos satisfatório. Esse resultado nos possibilita levantarmos duas questões: se, por um lado, apresenta-se como um resultado desanimador, pois, ao considerarmos todo o processo de intervenção, vemos que ele esteve voltado, em alguns momentos, para o desenvolvimento dessa competência, demonstrando ser uma das maiores dificuldades dos 
alunos; de outro, houve um aumento de 27, 27\%, demonstrando que eles apresentam alguma evolução em relação à habilidade exigida pelo descritor.

Os 59, 9\% de acertos, referentes ao descritor 4 - inferir uma informação implícita em um texto -, marcam também um pequeno crescimento, porém considerado satisfatório, já que o pré-teste acusou 51, $1 \%$ de acertos por parte dos alunos, obtendo um aumento de 5, 4\% e conseguindo manter-se acima da média: $51,1 \% \rightarrow 56,5 \%$. Considerando-se a dificuldade em recuperar informações que estão além da estrutura textual, o resultado apresenta-se como uma competência que os alunos já demonstravam desde o pré-teste.

Mensurando as competências de identificação de efeitos de ironia ou humor em textos variados e de identificação do efeito de sentido decorrente do uso da pontuação e de outras notações, os descritores 16 e 17, respectivamente, apresentaram um crescimento considerável: D16 (40, 9\%; $\rightarrow 52,17 \%)$ e D17 $(40,54 \% \rightarrow 72,72 \%)$, apontando para a apropriação por parte dos alunos das habilidades exigidas por ambos. O resultado relacionado ao último descritor apresenta-se como o melhor, dentre os outros observados anteriormente, representando um aumento de $68,18 \%$ em relação ao pré-teste.

Ainda em relação aos resultados satisfatórios, citemos o relacionado ao descritor 10, que determina que cada leitor seja capaz de identificar o conflito gerador do enredo e os elementos que constroem a narrativa. O grande salto - de 63,3\% para 86, 36\% - mostra que os alunos ampliaram a capacidade para reconhecer os elementos constitutivos da narrativa e estabelecer relações entre eles, apontando para o papel relevante da intervenção no trabalho com a competência que os resultados apresentavam como adquirida pelos alunos anteriormente ao pré-teste, auxiliando na manutenção da mesma. O resultado acima da média, demonstrado no pré-teste, é animador, pois, se considerarmos o tratamento dado pelo LD ao estudo da narrativa, constataremos que este aparece de maneira superficial, sendo aprofundado somente no E. M., período no qual a atenção se volta para a prova de redação e literatura, exigida no Vestibular.

Ao nos determos nos descritores 6 e 14, que exigem do leitor a capacidade de identificar o tema de um texto e distinguir um fato da opinião relativa a esse fato, comprovamos uma queda acentuada em relação a ambos: D6 - 59, 9\% $\rightarrow$ 34, 08\% e D14 $81,81 \% \rightarrow 31,81 \%$, correspondendo, respectivamente, a um déficit de $25,82 \%$ e $50 \%$. Os resultados constituem-se como competências que os alunos demonstravam possuir na fase de pré-teste e a não-manutenção destas no pós-teste, após o processo de intervenção didático- 
pedagógica. Infelizmente, este trabalho não nos permite analisar e comparar as questões relativas à abordagem com esse descritor.

Os descritores 7, 8, 11, 18 e 19, embora constassem apenas no pós-teste, apresentaram situação de aquisição diferenciada. Nos descritores 7 e 8 os alunos demonstraram competências, mas em relação aos descritores 18 e 19 que tratam de efeitos de sentido de expressões e de palavras no texto as quais exigem mais habilidades em leitura, os alunos não demonstraram competências.

\section{Considerações finais}

Após a execução do nosso projeto de pesquisa, constatamos que a maior dificuldade apresentada pelos alunos do $9^{\circ}$ ano do E.F, principalmente após a intervenção didática, está relacionada ao trabalho com o texto literário, ocasionada pelo caráter subjetivo que o constitui. Quando impelidos a atribuírem sentidos a textos do gênero crônica literária, os alunos interpretavam-no, em geral, dando o sentido denotativo de palavras e/ou expressões, sem ampliarem o olhar para a linguagem conotativa, da qual o texto literário está imbuído.

A percepção de tais dificuldades, que norteou a intervenção didático-pedagógica, permitiu um trabalho mais específico em que se objetivou a aquisição dessas competências leitoras não demonstradas no pré-teste. Após esse processo, verificamos que a intervenção didática se apresentou satisfatória, uma vez que propiciou oportunidades de aquisição e ampliação das competências não desenvolvidas mensuradas no teste citado - conforme dados na análise-, por meio do contato com a linguagem da crônica literária, abordando suas possibilidades de significação.

Ao analisarmos a formação do leitor competente, objetivo dos PCN-LP, observamos que o trabalho com essa especificidade de texto fez com que os alunos em foco, estimulados pela prática da leitura em sala de aula, abordassem-no de maneira mais reflexiva, resultado demonstrado na participação das aulas e no pós-teste.

Ainda em relação a essa formação, percebemos que, os descritores - mais especificamente, os descritores da Prova Brasil - apesar de parecerem fórmulas prontas e refletirem uma certa rigidez em relação à construção de uma visão crítica do aluno, aparecem como ponto de partida na composição de um universo amplo de interpretações. A 
identificação de efeitos de ironia ou humor em um determinado texto, por exemplo, é necessária para compreendê-lo em sua totalidade.

Diante das questões levantadas, constatamos que um maior contato com os textos literários, em que se atente para sua linguagem e sentidos, permite que o sujeito leitor seja capaz de perceber que o ato de ler pressupõe a união de elementos diversos na constituição do(s) sentido(s), sejam aspectos sócio-históricos e ideológicos, assim como de posse dessa habilidade, amplie sua formação e atuação como cidadão, sujeito leitor competente.

\section{Referências}

ALBUQUERQUE, M. S. P. A didatização do conceito de leitor competente dos PCN-LP no programa Parâmetros em Ação: mobilizando saberes teóricos e experienciais. Horizontes de Linguística Aplicada (UnB), v. 6, p. 10-128, 2007.

BORGATTO, Ana; BERTIN, Terezinha; MARCHEZI, Vera. Tudo é linguagem. $8^{\mathrm{a}}$ série. São Paulo: Ática, 2006.

BRASIL, Secretaria de Educação Fundamental. Parâmetros Curriculares Nacionais: primeiro e segundo ciclos do Ensino Fundamental. Língua Portuguesa. Brasília, MEC/SEF, $1998 b$.

Parâmetros Curriculares Nacionais: primeiro e segundo ciclos do Ensino Fundamental: Introdução. Brasília, MEC/SEF, 1998a.

Ministério da Educação. PDE: Plano de Desenvolvimento da Educação: SAEB: ensino fundamental: matrizes de referência, tópicos e descritores. Brasília: MEC, SAEB, Inep, 2008. 127 p. Disponível em: http://portal.mec.gov.br/dmdocuments/saeb_matriz2.pdf. Acessado em 20/05/2010.

FRANCO, Maria Amélia Santoro. Pedagogia da pesquisa-ação. Educação e Pesquisa. São Paulo, v.31, n. 3, p. 483-502, set./dez. 2005.

KATO, Mary A. O aprendizado da Leitura. 2. ed. São Paulo: Martins Fontes, 1987.

No Mundo da Escrita: uma perspectiva sociolinguística. 6. ed. São Paulo: Ática:

1998

KLEIMAN, Ângela. Leitura, Ensino e Pesquisa. Campinas: Pontes, 1989.

Texto e Leitor: aspectos cognitivos da leitura. 2. ed. Campinas: Pontes, 1992.

PERRENOUD, Philippe. Pedagogia diferenciada: das intenções à ação. Porto Alegre: Artmed Editora, 2002.

SOARES, Magda B. Letramento: um tema em três gêneros. Belo Horizonte: Autêntica, 1998.

SOLÉ, Isabel. Estratégias de leitura. Porto Alegre: Artes Médicas, 1998.

THIOLLENT, Michel. Metodologia da pesquisa-ação. 14. ed. São Paulo: Cortez, 2005.

VERÍSSIMO, Luis Fernando. Crônicas para se ler na escola. São Paulo: Objetiva, 2008.

ZILBERMAN, Regina. A Literatura Infantil na escola. 3. Ed. São Paulo/ SP: Global, 1983. 